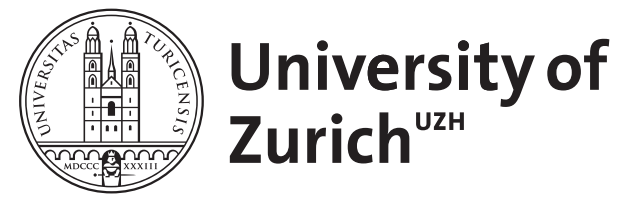

Zurich Open Repository and Archive

University of Zurich

University Library

Strickhofstrasse 39

CH-8057 Zurich

www.zora.uzh.ch

Year: 1992

Towards a quality-centered economic analysis: Some simple diagrams

Falkinger, Josef

DOI: https://doi.org/10.1111/j.1467-6435.1992.tb02755.x

Posted at the Zurich Open Repository and Archive, University of Zurich

ZORA URL: https://doi.org/10.5167/uzh-81675

Journal Article

Published Version

Originally published at:

Falkinger, Josef (1992). Towards a quality-centered economic analysis: Some simple diagrams. Kyklos, 45(4):469-482.

DOI: https://doi.org/10.1111/j.1467-6435.1992.tb02755.x 


\title{
Towards a Quality-Centered Economic Analysis: Some Simple Diagrams
}

\author{
JOSEF FALKINGER*
}

\section{INTRODUCTION}

The acknowledgement of the fact that commodities typically are not homogeneous but of different quality has stimulated economic theory extraordinarily. Market signaling and market screening when information about quality is asymmetric have become important subjects in modern microeconomic analysis (see e.g. KREPS [1990]). Quality selection, consumer information about quality or quality competition are central themes in the theory of industrial organization (see TIROLE [1988]). Also modern macroeconomics has profited substantially from dealing with quality. For instance, the dependence of quality on price serves as a microfoundation of rationing equilibria (cf. the survey of STIGLITZ [1987]), and unobservable product quality provides an explanation of price rigidity [ALLEN, 1988].

The purpose of the present paper is to put forward an economic analysis in which quality plays the key role that in usual economic analysis is played by the price. Conventional economic analysis takes quality as given and investigates how supply and demand are coordinated by the price. Also the literature mentioned in the above paragraph, though dealing explicitly with the problem of quality, concentrates on market coordination through prices. Supply and demand depend on both price and quality, but quality is seen as a function of the price and thus, ultimately, the (possibly deficient) coordination of supply and demand goes via the price (which now plays a double role as an indicator of scarcity as well as of quality at the same time). In contrast to this, the present analysis turns the conventional procedure on its head. It takes prices as given and considers market coordination by quality adjustments.

*Professor at the Institute of Public Economics, University of Graz, Austria. I wish to thank J. K. BRUNNER, R. DujMOVITS, J. ZWEIMULLER and an anonymous referee for helpful comments. 
To say that supply and demand are brought into balance by adjusting quality, instead of price, to its equilibrium value is of course exaggerated. However, undoubtedly the quality level in a market often changes with the market situation. On the one side, it is perfectly plausible that in a situation of excess demand quality deteriorates. One may think of diminishing service time per client and less careful production under pressure of time or of the use of lower quality inputs when pressure of demand is high. On the other side, with a shortage of demand producers want to attract more consumers by offering a higher quality level (and not only by lowering the price). Actually, disequilibrium situations in markets for products with varying quality level will induce both quality and price adjustments, and the market equilibria will be characterized simultaneously by equilibrium quality and equilibrium price. Thus, if this paper concentrates entirely on market coordination by quality, this is not meant so much as a perfect description of the real world but rather as a thought experiment which makes the point that quality matters (and not only, or sometimes not so much, the price) as clear as possible.

The paper proceeds as follows. In Section II a simple market model with coordination of supply and demand by quality is outlined. Section III considers policy impacts on the equilibrium level of quality in a single market. Especially, the effects of quality standards and consumer information on the equilibrium level of quality and quantity in the respective market are analyzed. Section IV applies the analysis to the standard model of the macroeconomic goods market. Section V contains a summary.

\section{MARKET COORDINATION BY QUALITY}

A good, characterized by a quality index $q$, is offered at price $p$. Let $x_{d}=D(p, q)$ and $x_{s}=S(p, q)$ be the corresponding demand and supply curve, where $x_{d}, x_{s}$ denote the demanded and supplied quantity, respectively. With respect to the partial derivatives, denoted by subscripts, the usual assumptions are made ${ }^{1}$.

Assumption 1: $D_{p}<0, D_{q}>0, S_{p}>0, S_{q}<0$.

The usual market diagram focuses on the price mechanism. Accordingly, it is drawn in the price-quantity space with $p$ and $x$ on the axes. Quality enters the

1. $D_{q}>0$ is a standard assumption (cf. TrRole [1988, p. 100]). It should be noticed, however, that the assumption is not necessarily fulfilled for any meaningful notion of quality (see e.g. NELSON [1991]). $S_{q}<0$ follows if price is equal to marginal cost and marginal cost increases with quality. 
picture as an exogenous parameter which shifts equilibrium price and quantity. To put quality (instead of the price) in the center of investigation means that the market analysis has to be carried out in the $(q, x)$-space. Measuring quality along the ordinate we have, according to Assumption 1, a positively declined demand curve and a negatively declined supply curve, respectively. They are represented in Figure 1. The market equilibrium, $E$, is now characterized by a certain equilibrium level of quality, $\bar{q}$.

Figure 1

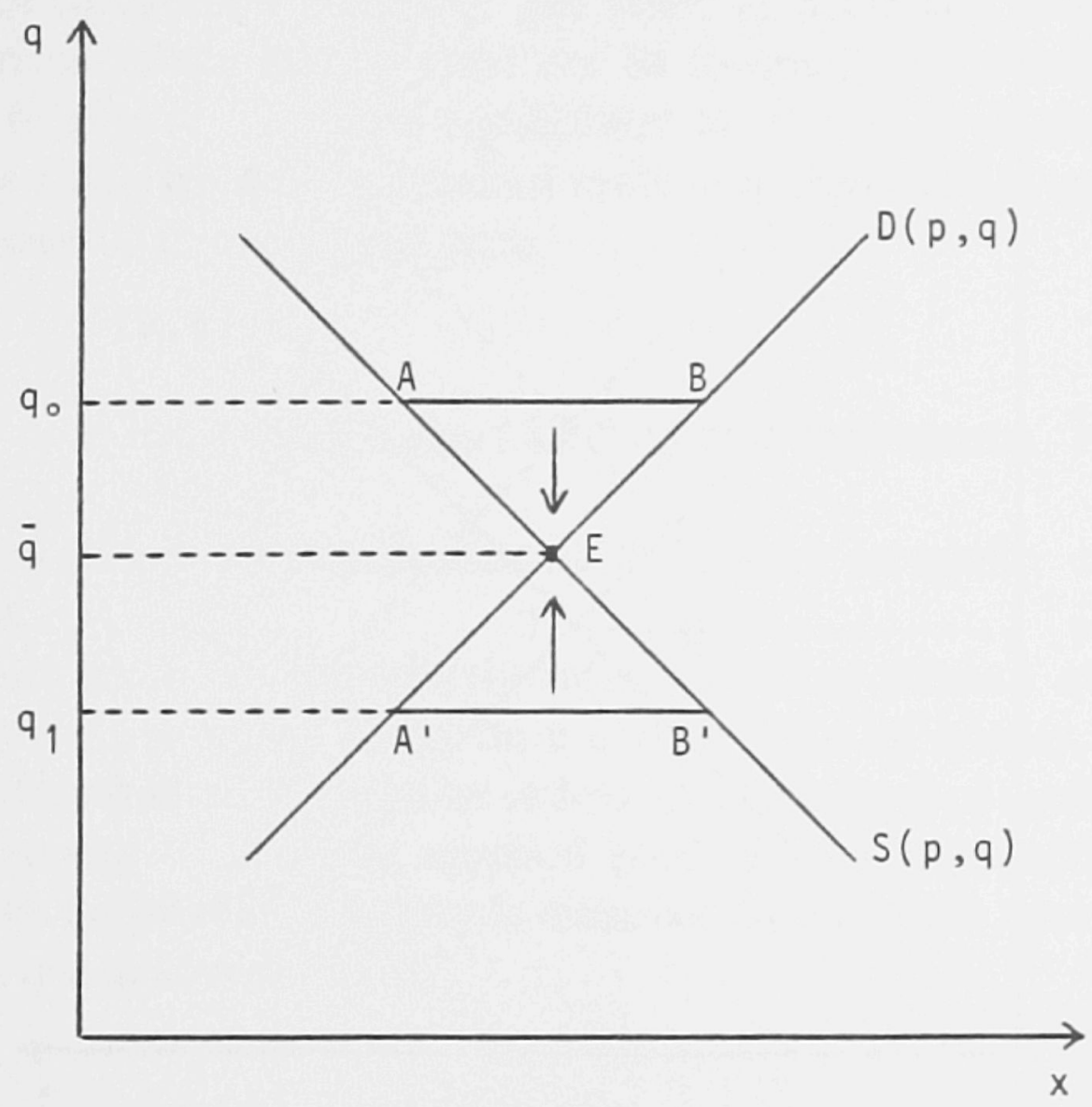

The question is, what happens if quality is out of its equilibrium value? Suppose $q_{0}>\bar{q}$. Then demand is in excess of supply (in Figure 1 the line AB represents the corresponding level of excess demand). As argued in the introduction, pressure of demand has a negative effect on the quality level of the goods supplied for various reason. The resulting pressure on input requirements leads to the use of less qualified inputs or the pressure on time makes production and service less careful. Thus, if $q 0>\bar{q}$ then the quality level is adjusted towards its equilibrium value $\bar{q}$ and excess demand is reduced. Consider now $q_{0}<\bar{q}$. In this case demand falls short of supply and producers will raise the quality level of their supply in order to attract more consumers. Again, the quality level 
is adjusted towards the equilibrium value $\bar{q}$. These considerations show that the diagramm presented in Figure 1 represents a meaningful tool for the analysis of market coordination by quality.

The price of the relevant good enters the picture as an exogenous parameter. Suppose for example that $p$ rises to $p^{\prime}$. Then, according to Assumption 1, the supply curve is shifted to the right and the demand curve is shifted to the left, respectively. The situation is represented in Figure 2.

Figure 2

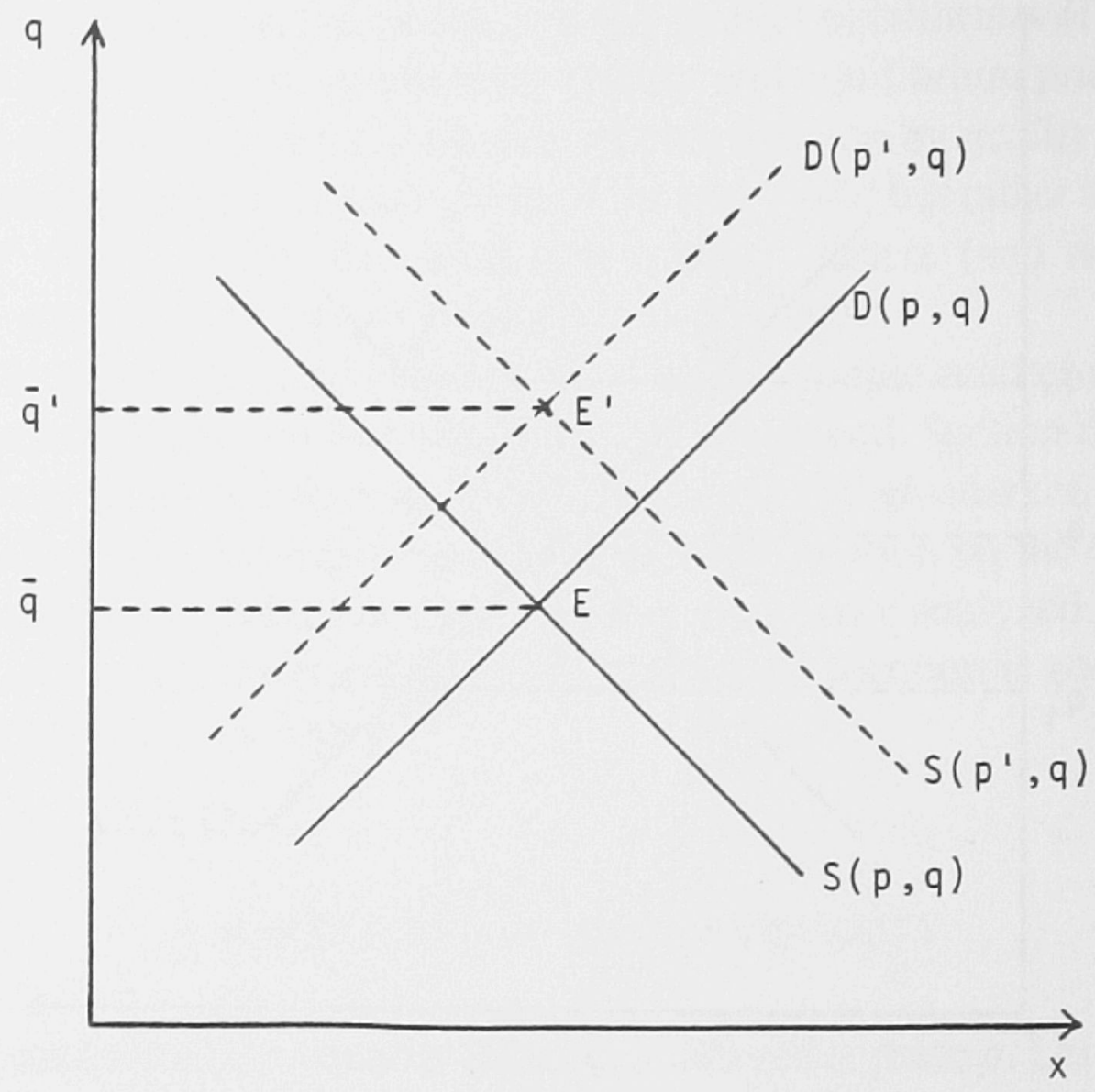

As a result, the market equilibrium is moved from point $E$ to $E$ ' which corresponds to a comparatively higher level of equilibrium quality, $\bar{q}$ '. The impact on the equilibrium level of quantity cannot be determined without more specific assumptions.

The further analysis will show that the simple diagrams presented in this section are an efficient and elegant tool for discussing interesting economic problems in the sphere of industrial organization and of macroeconomics. 
TOWARD A QUALITY-CENTERED ECONOMIC ANALYSIS

III. POLICY IMPACTS ON THE EQUILIBRIUM LEVEL OF QUALITY

The purpose of this section is to analyze the effects on product quality of some common policy measures like quality standards and consumer information.

\section{Quality Standards}

Suppose that a restriction $q \geq q_{0}$ for some standard $q_{0}>\bar{q}$ is introduced in a market with equilibrium quality $\bar{q}$. The result is, according to Figure 1 , an excess demand. Since quality must not be lowered, prices may rise until, according to Figure 2, a new equilibrium at $\bar{q} \geq q_{o}$ is reached. In sum, introducing a binding quality standard leads to higher product quality and to excess demand or an increase of price.

\section{Uncertain Quality and Consumer Information}

A less trivial task is the clarification of the impact on quality of consumer information.

Consumers are often imperfectly informed about product quality. That means, demand cannot be based on a certain value of quality. Rather the consumer is confronted with a more or less uncertain level of quality. Let $q$ be the actual quality level of the supplied good. For an imperfectly informed consumer the judgement of quality is disturbed by a random term $\varepsilon$ so that to him quality is a random variable

$$
\tilde{q}=q+\varepsilon .
$$

Now, imperfect information about quality can mean two things. The consumer can have wrong expectations or he is (more or less) uncertain that he gets the expected quality. The following definitions make this distinction precise:

i) Consumers have wrong expectation of quality, if $E(\varepsilon) \neq 0$ and thus $E(\widetilde{q}) \neq q$.

ii) Given $\tilde{q}=q+\varepsilon, \tilde{q}^{\prime}=q+\varepsilon^{\prime}$ with $E(\varepsilon)=E\left(\varepsilon^{\prime}\right)$. Consumers have a higher quality risk if $\varepsilon^{\prime}>R S \varepsilon$ and thus $\tilde{q}$ ' $>R S \tilde{q}$, where $>R S$ denote the Rothschild and Stiglitz ordering of risks. 
Since quality is now a random variable for the consumer, the concept of the demand curve as a function of quality and price must be reconsidered. The natural modification of $D_{q}>0$ (Assumption 1), is to assume that, given the quality risk, demand increases with expected quality.

Assumption 2: Suppose, $\tilde{q}^{\prime}=R s \tilde{q}$. Then, $D\left(p, \tilde{q}^{\prime}\right)>D(p, \tilde{q})$ if $E\left(\tilde{q}^{\prime}\right)>E(\tilde{q})$.

The dependence of demand on the risk of $\tilde{q}$ is less evident. A plausible assumption is that consumers react to quality risk with caution ${ }^{2}$. Accordingly, we formulate

Assumption 3: Suppose, $E\left(\tilde{q}^{\prime}\right)=e(\widetilde{q})$. Then, $D\left(p, \tilde{q}^{\prime}\right)<D(p, \tilde{q})$ if $\tilde{q}^{\prime}>R s \tilde{q}$.

Policy measures providing consumers with information about product quality can thus have the following impacts.

Figure 3

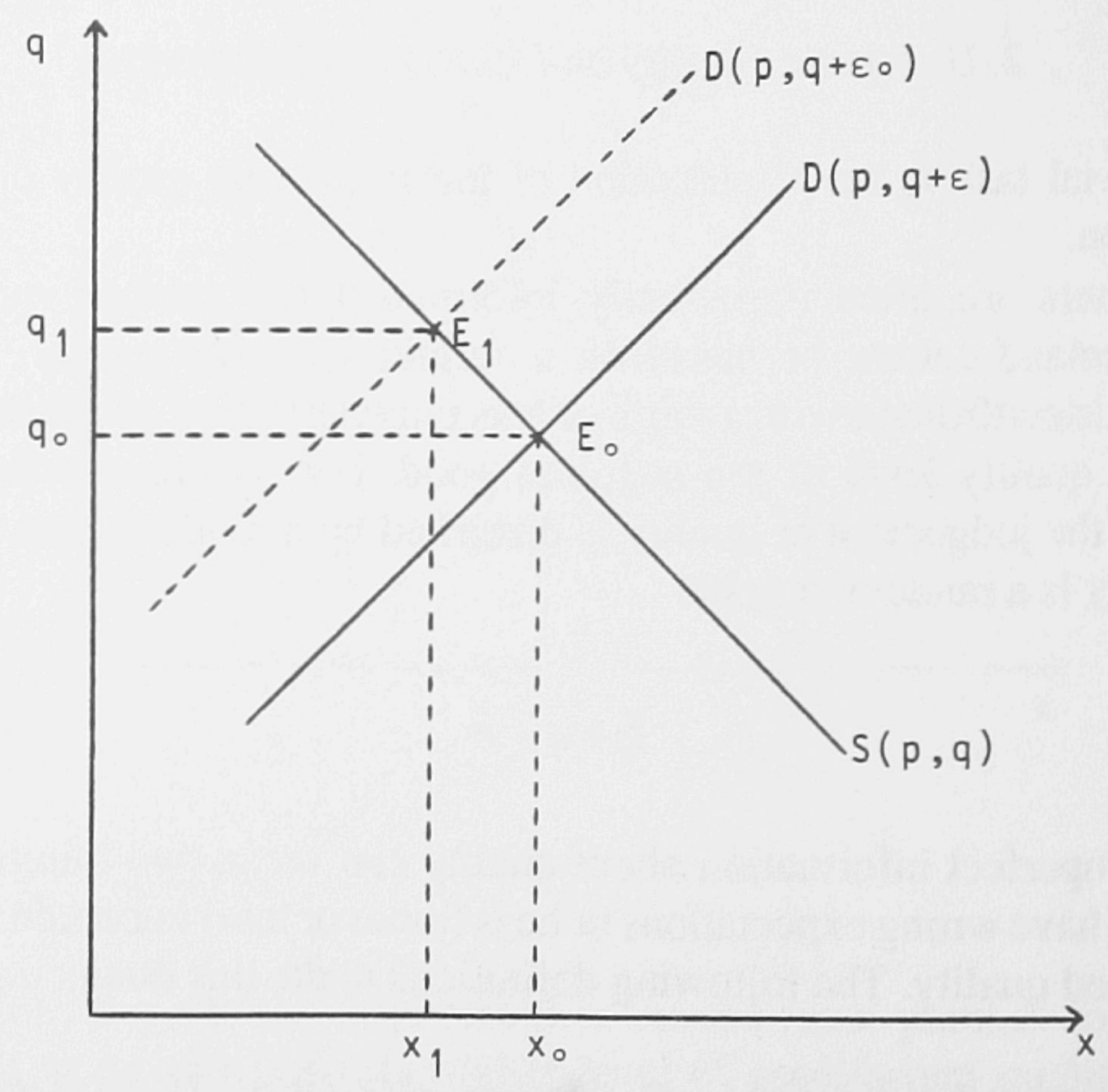

2. Admittedly, we do not have a decision-theoretic argument, which generally excludes that consumers buy comparatively more if quality is risky. In that case, which however seems less plausible intuitively, the sign of the risk effects analyzed in this section would be reversed. 
First, they may correct a wrong expectation of quality. Formally, they correct $\varepsilon$ with $E(\varepsilon) \neq 0$ to $\varepsilon_{o}$ with $\varepsilon_{o}=R S \varepsilon$ and $E\left(\varepsilon_{o}\right)=0$. According to Assumption 2, that means, the demand curve is shifted to the left (to the right) if $E(\varepsilon)>0$ (if $E(\varepsilon)<0$, respectively). Figure 3 illustrates the situation for the case $E(\varepsilon)>0$, that is, if consumers overestimate the quality level before they become informed about the true quality that can be expected.

Consumer information shifts the market equilibrium from point $E_{o}$ to $E_{1}$. So it increases quality and decreases quantity in the relevant market. Obviously, if consumers underestimate quality before they become informed, then the effects are reversed.

Secondly, policy measures providing information about product quality to consumers may change the uncertainty about actual product quality, given its expected level. Let $\varepsilon, \varepsilon^{\prime}$ with $E(\varepsilon)=E\left(\varepsilon^{\prime}\right)$ represent the relevant quality risks before the provision of information about product quality to the consumer and after the provision of information, respectively.

Figure 4

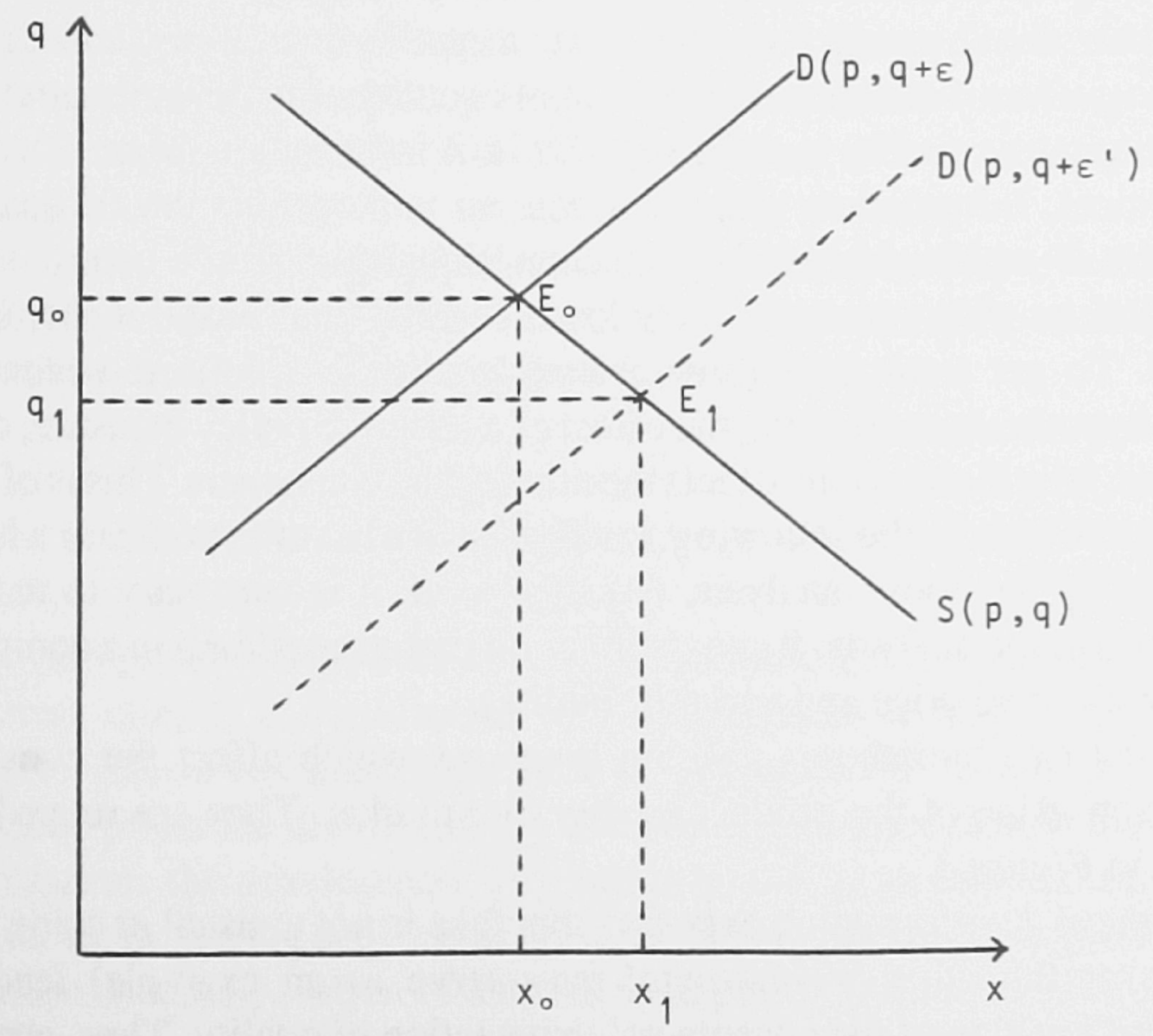


Usually, information will reduce uncertainty about quality. That means, $\varepsilon '<R S \varepsilon$. According to Assumption 3, the demand curve is shifted to the right in this case. See Figure 4. As a result, quality decreases and quantity increases in the relevant market. At first glance, the conclusion that consumer information about product quality decreases the equilibrium level of quality in the respective market is somewhat surprising. The reason behind this result is that with less uncertainty about quality a lower level of quality suffices to induce a certain level of demand.

However, providing the consumer with information about product quality may also increase his uncertainty. Note that it is the consumer's subjective view which is relevant for demand behavior. If a consumer becomes better informed, then he sees the true risk more clearly. It may be higher than the consumer's view of the risk before information. One could also say, consumers become more critical in the sense that they are increasingly aware of the variability of quality in the market. In this case, $\varepsilon^{\prime}>R S \varepsilon$. According to Assumption 3 , the demand curve is shifted to the left. As a result, quality increases and quantity decreases in the considered market.

Summing up, one can say that measures which provide consumers with information about product quality have a quality-increasing and quantitydecreasing effect if consumers overestimate quality or underestimate the variability of product quality in a market; that is, if information makes consumers more critical. Information which corrects an underestimation of quality by consumers or which reduces the consumer's quality risk in a market leads to an equilibrium with a comparatively lower level of quality and higher level of quantity. To get from these general conclusions to a definite statement or testable hypothesis concerning the effect of a concrete policy measure, one has to find out, how the measure affects the mind of the consumers. This is of course a speculative task. In the following, I will present a list of hypotheses which are suggested by the above analysis. (At this point, it is necessary to recall the restrictions of the analysis. It concentrates on partial equilibria in a competitive market with fixed price and variable quality).

The first two hypotheses concern measures which affect the consumers' expectation value of the product quality in a market. They are related to the analysis in Figure 3.

Hypothesis 1: Information exposing that fake is not unusual in some branch (the one or the other Weinskandal may serve as an example) leads to a downward revision of the consumers' expectation of quality. Thus, according to the above analysis, a scandal induces an increase of product quality and a reduction of quantity in the respective market. 
Hypothesis 2: Cooperative campaignes to raise the image of a branch, if successful, lead to an upward revision of the consumers' expectation of quality. According to the above analysis, the induced shift of market equilibrium is characterized by a comparatively lower level of quality and a higher level of quantity.

The next two hypotheses deal with measures which affect the consumers' uncertainty about product quality. They are related to the analysis in Figure 4.

Hypothesis 3: General consumer education tells consumers to be aware of the variability of quality supplied. Thus it increases the consumers' uncertainty and, according to the above analysis, leads to an increase of quality and decrease of quantity in all markets with imperfect quality information.

Hypothesis 4: Specific Consumer Reports or Warentests reduce the quality risk for the consumer. Thus, the diffusion of such tests and reports, leads to a shift of the market equilibrium towards more quantity and a comparatively lower quality level.

The last two hypotheses describe possible dynamics suggested by the above analysis. The idea is that true product quality is detected with time.

Hypothesis 5: Consumers' expectation of quality is revised downwards/upwards if the quality of the product is overestimated/underestimated, respectively. Thus, according to the analysis in Figure 3, the quality level will rise and quantity decline in a market with initially overestimated products, and vice versa if the quality of a newly introduced product is underestimated at the beginning.

Hypothesis 6: Experience and learning reduces the quality risk. Thus, the above analysis (Figure 4) predicts that, other things being equal, the market size increases and the quality level declines with time.

\section{THE MACROECONOMIC GOODS MARKET}

The relevant price in conventional macroeconomic goods-market analysis is the interest rate, i. It coordinates the consumption-savings behavior with investment decisions. Pursuing the idea that consumer decisions are not only governed by prices but also by quality, one comes to the conclusion that besides the interest rate the development of product quality is an important factor for the consumption-saving decision and thus for the macroeconomic goods market equilibrium. Recently, different authors have put forward models of long-run growth based on endogenous product innovations which upgrade quality over time (see SEgERSTROM, ANANT and DiNOPOULIS [1990], GROSSMAN and HELPMAN [1991] and the references there). The following considerations concentrate on short-run problems and take the development of quality as given. 
Let $q_{o}, q_{1}$ be the (index of) present and future quality of consumption goods, respectively.

\section{The Consumption and Saving Decision}

Consumers have common preferences. Utility in period $t$ is a function, $u\left(c_{t}, q_{t}\right)$, of income spent on consumption, $c_{t}$, and of the quality of the consumption goods, $q_{t}$. Assumption 4 summarizes standard assumptions concerning marginal utility.

Assumption 4: $u_{c}>0, u_{q}>0, u_{c c}<0, u_{c q}>0$.

For deciding how much of his present income, $y$, he spends and how much he saves, the consumer maximizes the sum of present and (discounted by some factor $\delta$ ) future utility, subject to the budget constraint

$$
\begin{gathered}
U=u\left(c_{o}, q_{0}\right)+\delta u\left(c_{1}, q_{1}\right), \\
c_{1}=(1+i)\left(y-c_{o}\right) .
\end{gathered}
$$

(The price level is held constant.)

To avoid aggregation problems, homothetic preferences are usually assumed. Thus, suppose that $u$ is homogenous in $c$. Then, maximization of (2) (under restriction (3)) with respect to $c_{o}$ is equivalent to maximization of

$$
U=u\left(z, q_{o}\right)+\delta u\left((1+i)(1-z), q_{1}\right)
$$

with respect to $z \equiv c_{o} / y$.

The first-order-condition for $z$ is:

$$
F=\partial u\left(z, q_{o}\right) / \partial c-\delta(1+i) \partial u\left((1+i)(1-z), q_{1}\right) / \partial c=0
$$

For a given interest rate, it defines the propensity to consume as a function, $z\left(q_{o}, q_{1}\right)$, of present and future product quality. Because of the homogeneity assumption, the propensity to consume does not vary with the consumer's income. Differentiating $F$ implicitly, we get, under Assumption 4,

$$
\partial z / \partial q_{o}>0 \text { and } \partial z / \partial q_{1}<0
$$


Since the propensity to consume, defined by condition (5), is independent of the consumer's income (due to the homogeneity assumption), aggregate consumption, $C$, is given by the equation

( $Y$ denotes aggregate income).

$$
C=z\left(q_{o}, q_{1}\right) Y .
$$

\section{The IS-Curve in the Quality-Income Space}

It is problematical to argue that also investment behavior is governed by the development of product quality. Only questionable assumptions concerning the dependence of investment on quality could be made. Therefore, the more adequate procedure is to see investment independent of quality. Let $I$ be the exogenously given level of investment. Then, in view of (7), the goods market equilibrium is characterized by the condition

$$
Y=I /\left[1-z\left(q_{o}, q_{1}\right)\right] .
$$

Figure 5

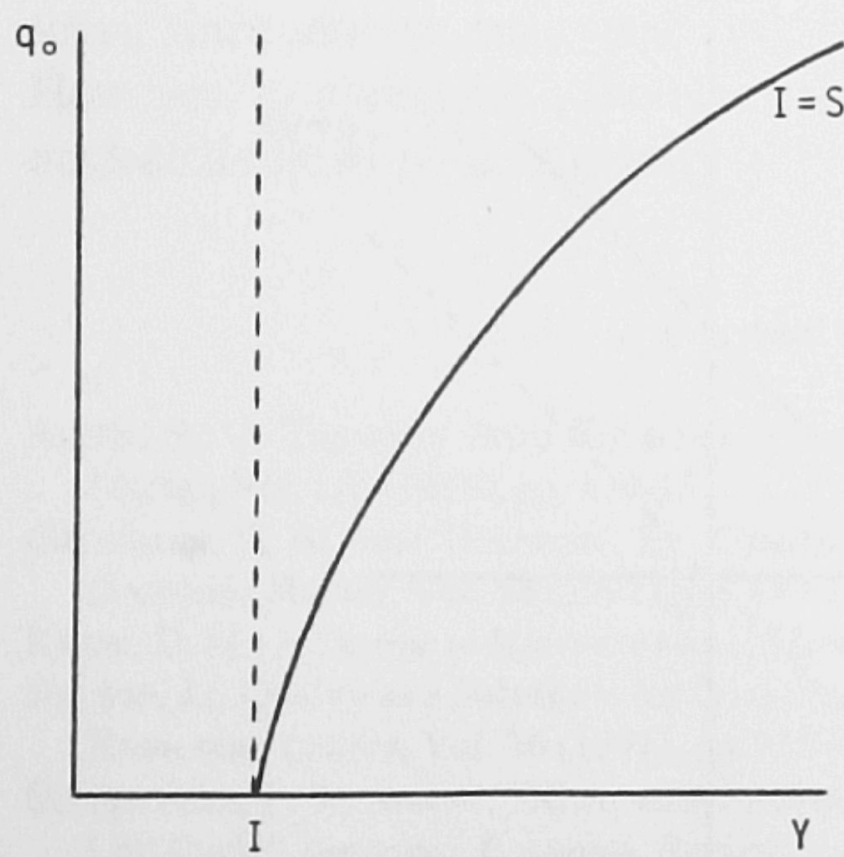

a)

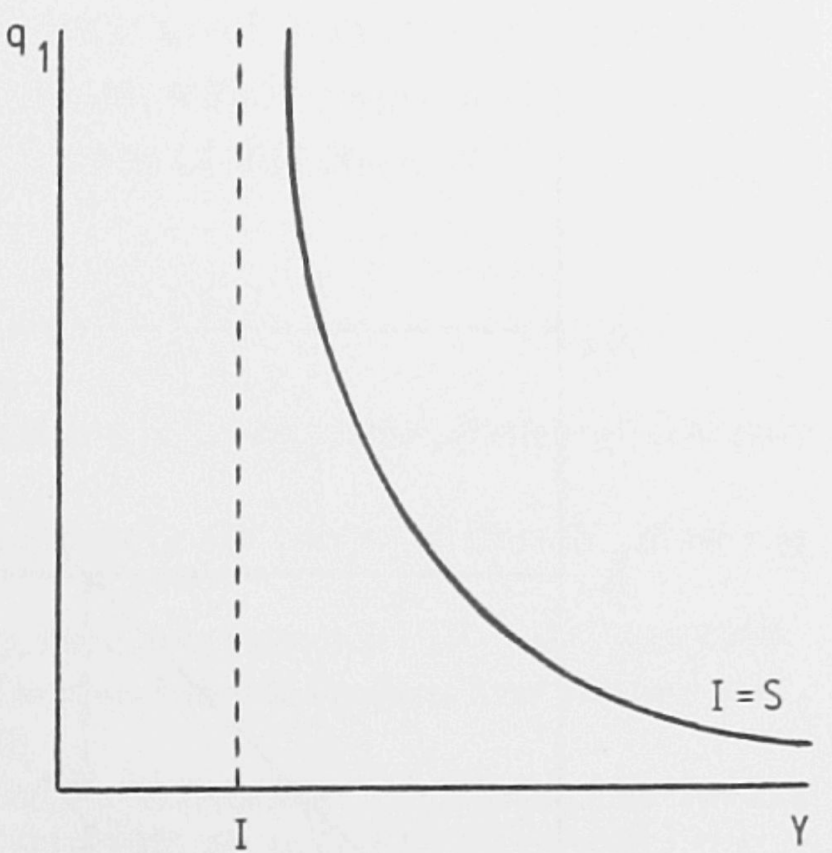

b) 
Using (6), one can draw the corresponding IS-curve in the quality-income space. We find that the IS-curve is positively sloped in the $\left(Y, q_{o}\right)$-space and negatively sloped in the $\left(Y, q_{1}\right)$-space. The precise shape of the curves is of course not determined. Figure $5 a$ and $b$ present stylized versions of these IS-curves (where $z\left(0, q_{1}\right)=z\left(q_{o}, \infty\right)=0$ and $z\left(q_{o}, 0\right)=z\left(\infty, q_{1}\right)=1$ is assumed).

\section{Product Quality and the Problem of Effective Demand}

The IS-curve describes the possible goods market equilibria. A problem of effective demand arises if the realized equilibrium income falls short of the full employment level. The point of this paper is to concentrate on quality adjustments (instead of the usually considered mechanism of price adjustments) in the analysis of markets. The relevant price in the macroeconomic goods market is the interest rate, and a problem of effective demand arises if the interest rate does not fall to the level corresponding to full employment. Now, the present

Figure 6

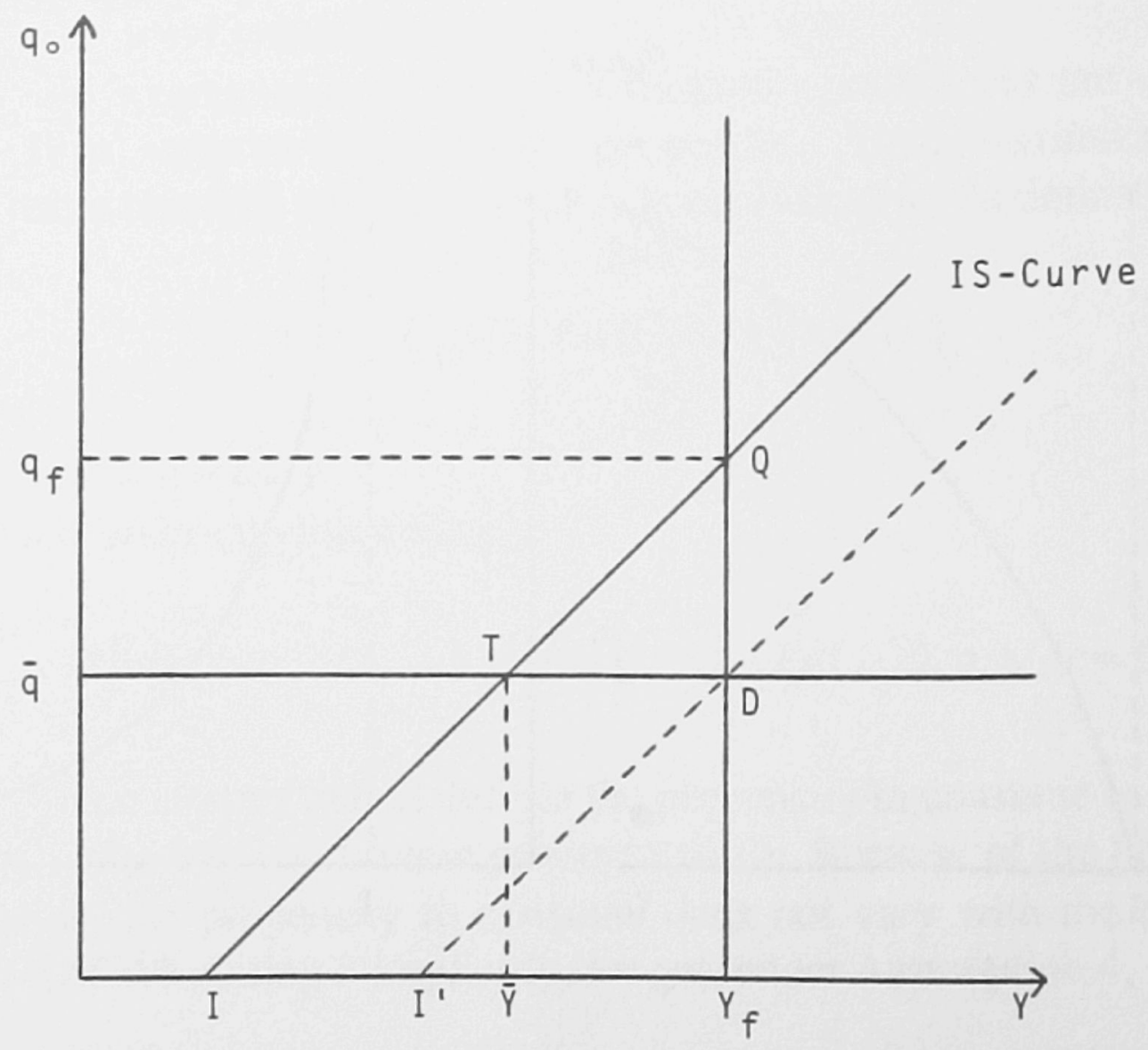


analysis takes the interest rate as given and concentrates on the role of present and future product quality. Accordingly, a problem of effective demand arises if, for whatever reasons, quality does not adjust to the level corresponding to full capacity. This is illustrated in Figure 6.

Let $Y_{f}$ be capacity output. Then, the level of present quality (given future quality), which guarantees that full employment is realized, is $q_{f}$. If actual product quality is restricted by some upper limit $\bar{q}<q_{f}$, then only the underemployment equilibrium income $\bar{Y}$ will be realized. Possible reasons for the existence of an upper limit of quality are technical bottlenecks (for instance lack of high-quality inputs or of high precision machinery), education and training problems but also institutional arrangements like patent restrictions. (Of course, one could draw an analogous diagram with respect to future quality. It is easy to see that an underemployment equilibrium results if future quality is restricted by some lower bound. That means, if the consumer's expectations concerning future quality are so high that they save too much).

As far as economic policy is concerned, Figure 6 shows that in principle three types of policy measures exist by which an underemployment equilibrium can be overcome. First, quality-independent expansion of demand shifts the relevant IS-curve to the right so that the full-employment equilibrium $D$ is realized. Secondly, labor-supply management reduces capacity output to $\bar{Y}$ so that $T$ becomes a full-employment equilibrium. Or, finally, measures promoting and diffusing high quality production shifts the quality restriction upwards until the equilibrium point $Q$ is reached. Of course, these are very partial considerations, since interest rate, wage rate and price level matter in the real world. However, to undertake a thought experiment which emphasizes the usually neglected role of product quality is the purpose of this analysis.

\section{REFERENCES}

ALlen, F.: 'A Theory of Price Rigidities When Quality is Unobservable', Review of Economic Studies, Vol. LV (1988), pp. 139-151.

Grossman, G. M. and Helpman, E.: 'Quality Ladders in the Theory of Growth', Review of Economic Studies, Vol. 58 (1991), pp. 43-61.

KREPS, D. M.: A Course in Microeconomic Theory, Princeton: Princeton University Press, 1990.

Nelson, J.: ‘Quality as a Substitute for Quantity. Do More Reliable Products Ever Sell for Less?', Economics Letters, Vol. 36 (1991), pp. 239-243.

Segerstrom, P. S.; ANANT, T.C.A. and Dinopoulos, E.: 'A Schumpeterian Model of the Product

Life Cycle', American Economic Review, Vol. 90 (1990), pp. 1077-1091.

STIGLitz, J. E.: 'The Causes and Consequences of the Dependence of Quality on Price', Journal of Economic Literature, Vol. XXV (1987), pp. 1-48.

TIROLE, J.: The Theory of Industrial Organization, Cambridge/M.: MIT Press, 1988. 


\section{JOSEF FALKINGER}

\section{SUMMARY}

This paper puts the role of product quality in the market game of supply and demand into the center of the analysis. To that purpose it provides a systematic investigation of market diagrams with quality instead of price on the ordinate. This new focus allows interesting conclusions by simple application of well-known diagrammatic methods. For instance, as far as single markets are concerned, it is shown that providing consumers with information about product quality may increase or decrease quality in the market, depending on the type of information provided. Another conclusion of practical relevance, conceming the macroeconomic activity level, is that an effective demand problem may be caused if present product quality is too low compared with the product quality expected for the future.

\section{ZUSAMMENFASSUNG}

Die vorliegende Arbeit versucht, die Rolle der Produktqualität für das Zusammenspiel von Angebot und Nachfrage ins Zentrum der ökonomischen Analyse zu rücken. Dazu werden Marktdiagramme mit einem Qualitätsindex anstelle des Preises konstruiert und untersucht. Analog zu den üblichen komparativ-statischen Analysen mit Marktdiagramm wird die Rolle der Produktqualität in verschiedenen mikro- und makroökonomischen Fragestellungen untersucht. Insbesondere wird gezeigt, wie Konsumenteninformation je nach Art der Information zu einer Steigerung oder Senkung der Qualität im betreffenden Markt führen kann. Eine andere, makroökonomisch relevante Schlussfolgerung ist zum Beispiel, dass es zu einem Problem der effektiven Nachfrage kommt, wenn das gegenwärtige Qualitätsniveau der Produkte im Vergleich zu dem für die Zukunft erwarteten zu niedrig ist.

\section{RÉSUMÉ}

Cet article analyse la rôle, que joue la qualité d'un produit pour l'équilibre de l'offre et de la demande sur le marché. Pour cela des diagrammes du marché sont construés que montrent à l'axe des coordonnées un indice de qualité au lieu du prix. Avec ces diagrammes des analyses comparatif-statiques sont effectuées pour examiner la rôle de la qualité dans divers problèmes micro- et macroéconomiques. En particulier il est exploré, comme l'information des consommateurs peut induire une augmentation ou une réduction de qualité sur le marché selon les circonstances. Une autre conclusion est par example, qu'un problème de demande effective résulte, si le niveau actuel de qualité est trop bas en comparaison au niveau futur. 
Copyright of Kyklos is the property of Wiley-Blackwell and its content may not be copied or emailed to multiple sites or posted to a listserv without the copyright holder's express written permission. However, users may print, download, or email articles for individual use. 